\title{
Research on Sports Dancing to Healthy Development of College Students' EQ
}

\author{
Guan Yi, Gong Yuning \\ Sport and Art Department, Chengde Petroleum College, Chengde China
}

\begin{abstract}
- by the methods of literature, experiment method, the experiment in teaching reform of teaching methods, using the methods of the mental skill training in goal setting training, has the influence to the Haunches Science and Technology College 2008 Dance Sport Specialized Course Students Eq. The result shows: the students' Estuation needs to be improved, the first $12.5 \%$ student not reach normal value 90; boys whole EQ is slightly higher than girls; goal setting training before and after the experiment, students emotional intelligence mean difference $6, \mathrm{~T}$ value is 5.542, significant at $0, \mathrm{P}<0.05$, there was significant effect experiment. Conclusion: the increase of EQ education for college students to; create teaching situation, raise the students EQ in practice; in sports dance teaching, reform teaching methods, using the methods of the mental skill training in goal setting training, the students' emotional healthy development to have the promotion effect.
\end{abstract}

Index Terms - the healthy development, sports dance teaching emotion

\section{Introduction}

Emotional quotient (EQ) is a recently proposed to IQ (IQ) in terms of psychological concepts; it is a reflection of personal emotional control and external pressure to grasp his mental balance and other non intellectual factors. Professor Daniel of the Harvard University, Gellman believes American "emotional intelligence is the key to success in life". A large number of facts prove, that a successful person, have higher emotional quotient (EQ) quality. Therefore, in modern times put forward the new idea of success: success factors of emotional intelligence (EQ) accounted for $80 \%$, IQ (IQ) $20 \%$. This innovative concept of intelligence the first era ended also cracked the code of success. [1]

EQ is English Emotional Quotient (EQ) abbreviation, Chinese means emotional quotient, relative and IQ IQ, EQis the main innovation in it summed up the success factors of people searching for. Including: A, self awareness. Two, self motivation. Three, self control. Four, the feelings of others. Five, the interpersonal relationship. [2] self understanding is the first element of emotional intelligence, self understanding to dominate their own destiny, "know yourself as well as the enemy, know yourself"; self motivation is a kind of ability, is the key to success, is the first secret of success, it can adjust the emotional gap, effective anti frustration, through suffering, and suffering into wealth; self control emotional quotient(EQ) of the core, is the management of emotion and behavior restraint, overcome impulses, resist the temptation, to curb excessive desire; others, for the good of others, empathy, and others emotions is a virtue; interpersonal relationship is to coordinate the relationship between man and man, is an important link of a collective and career success now the social life, is a skill and knowledge, the winner is often more interpersonal relationship.

Plays an important role in the development of human intelligence. An "EQ" tall person, often can clearly understand and grasp their own emotional, sensitive emotions of others and feedback the emotions of others effectively, often can be in every aspect of life, occupy the time, location, and other aspects of the advantages. The lives of these people are often more efficient, more easily satisfied, can use their intelligence to obtain fruitful results.

However, the EQ is not immutable and frozen; it is can improve slowly through the subjective efforts. [3] So, in teaching, and promote the healthy development of College Students' EQ is our bounden duty and obligation education. Sports dance have eliminate fatigue, edify sentiment, rehabilitation of the body, eliminate the psychological barriers and adjusting interpersonal relationships, teaching in the past, most of the students is a fixed partner, resulting in a lot of students for the partner jump not good, boys or girls feel shy to invite her, wouldn't accept the invitation or boys, interactive classroom atmosphere. Don't wait for a phenomenon, in the normal teaching goals, tasks at the same time, the use of psychological skills training methods of goal setting training, to develop a special target -- exchange partner to students, through the training methods of psychological skills in goal setting training, a destination for students EQinfluence, make it more clear self recognition, self motivation, control, in order to improve the students to overcome the psychological barrier of interpersonal, cultivate their good communication quality, increase the ability of social adaptation. At the same time, in order to improve the reform of teaching methods and means of sports dance course for college students of sports dance, interest, to provide some ideas.

\section{Object and Method of Study}

A. Research subjects:2008 Chengde Petroleum College Dance Sport Specialized Course of students' EQ

\section{B. Rresearch methods}

1) The documentation in the library, Zhengzhou University Library of Zhengzhou University sports department reference room, the library of Chengde Petroleum College, Chengde Petroleum College, Institute of physical education and the use of computer network literature retrieval, consult and collect a large amount of relevant information.

2) Experiment (target setting) experimental design

Goal setting is one of the methods of motivation, it by setting specific targets; make it become the motivation of individual effort motivation, so as to improve the activity 
score.

The variables of experiment:

Due to the change of variable $1=$ students self understanding

The dependent variable $2=$ change students' self motivation

The dependent variable 3 = change students' self control

Due to the change of variable $4=$ students of the feelings of others

Change the dependent variable $5=$ students interpersonal relationship

Variable $=$ set up special short-term goals

The starting level control variables = teaching plan, the students of sports dance

Covariant $=$ student gender

The tracking time: 8 weeks

Study motivation: In the teaching of sports dance in addition to the completion of the normal teaching objectives, the use of psychological skills training methods of goal setting training, a destination for students' emotional intervention, of goal setting on students' EQ (self understanding, self motivation, self control, feelings of others, interpersonal relationship) effect.

Thestudy: Goal setting training on students' EQ (self understanding, self motivation, self - control, the feelings of others, interpersonal relationship) would affect? Before and after the experiment is to form the difference?

Experimental hypothesis: The use of psychological skills training methods of goal setting training, have a great effect on students' emotional health development.
Subject design: The subjects of this research were selected from grade 2008 of Chengde Petroleum College sports dance elective class students, according to the public sports curriculum arrangement, then select Tuesday morning sports dance class of 40 students, including 20 boys, 20 girls, gender proportion.

The subjects of sports dance learning the starting level, the second grade students for University, is the year beginning September professional sports dance, just learned the waltz, now began to study Beijing ping.

Measurement tooled test standard scale

Experimental procedures:

(1) The EQ on students before the experiment (self understanding, self motivation, self - control, the feelings of others, interpersonal relationship) test;

(2) After the end of the experiment the students' emotional intelligence tests. (Fill in, by the students of the independent record.)

Data processing. All experimental data using SPSS16 software, analysis.

\section{Results}

A. Of the students before and after the experiment, the EQ of descriptive statistics

Experiment teaching reform, application of goal setting (short term) to psychology, to intervene in students. Before and after the experiment, the experimental group students' EQ (self understanding, self motivation, self - control, the feelings of others, interpersonal relationship): using average, standard deviation said.

Table1. Describe the before the experiment group students' status

\begin{tabular}{|c|c|c|c|c|c|c|}
\hline & EQ & Self awareness & Self excitation & Self control & The feelings of others & Interpersonal relationship \\
\hline The effective number & 50 & 50 & 50 & 50 & 50 & 50 \\
\hline The minimum value & 69 & 17 & 3 & 11 & 9 & 11 \\
\hline The maximum value & 145 & 48 & 30 & 42 & 20 & 20 \\
\hline The mean & 101.43 & 29.4 & 16.05 & 26.6 & 15 & 17.23 \\
\hline Standard deviation & 18.358 & 8.356 & 5.51 & 7.125 & 3.889 & 2.323 \\
\hline
\end{tabular}

Table 2 the experimental group students' EQ status description

\begin{tabular}{|c|c|c|c|c|c|c|}
\hline & EQ & Self awareness & Self excitation & Self control & The feelings of others & Interpersonal relationship \\
\hline The effective number & 50 & 50 & 50 & 50 & 50 \\
\hline The minimum value & 67 & 19 & 9 & 11 & 12 \\
\hline The maximum value & 157 & 48 & 29 & 45 & 20 \\
\hline The mean & 106.6 & 30.25 & 15.88 & 27.25 & 14.13 \\
\hline Standard deviation & 15.379 & 8.092 & 5.07 & 6.827 & 3.736 \\
\hline
\end{tabular}

Table 3 the students in the experimental group before and after experiment, EQ status

\begin{tabular}{|c|c|c|c|c|c|c|}
\hline & EQ & Self awareness & Self excitation & Self control & The feelings of others & Interpersonal relationship \\
\hline The effective number & 50 & 50 & 50 & 50 & 50 \\
\hline The minimum value & 68 & 19 & 7 & 10 & 10 \\
\hline The maximum value & 153 & 49 & 29 & 43 & 20 \\
\hline The mean & 106.63 & 30.25 & 15.88 & 27.25 & 14.13 \\
\hline Standard deviation & 15.379 & 8.092 & 5.07 & 6.827 & 3.736 \\
\hline
\end{tabular}




\section{B. Aired samples $T$ test results}

The before and after the experiment, the data were paired samples $\mathrm{T}$ test analysis, display results: goal setting teaching before and after the experiment, students' emotional intelligence mean difference $6, T$ value is 5.542 , significant at 0 . The experiment has significant effect.

\section{Conclusion}

A. Current situation needs to improve college students' $E Q$

Research shows that: the first $12.5 \%$ student EQ not reach normal value 90 . The cause of College Students' health problem is in many aspects, both personal problems, have a family, society, school problems. Examination oriented education years caused most schools focus more on memory, thinking and other aspects of analysis, to improve the ability of college students Gaofendineng, who It is often seen., this "low" in large part refers to the underdeveloped Eq. Some of the students self, lonely, some sense of inferiority, depression; there are some students self-control ability is poor, love impulse; there are many students selfish, lack of love and the spirit of cooperation. The students' EQ is low, is not conducive to individual development, but also meet the requirements of social development. Emotional intelligence is a kind of ability, and ability is to cultivate, so it is very important to the EQ education for college students.

\section{B. The goal setting (short-term) psychology intervention on the students, more significant effect}

From the survey situation, boys whole EQ is slightly higher than girls, boys high EQ is 142 , the highest for the 128boys girls emotional intelligence; the bottom EQ is 78, the lowest for 65 girls EQ: before the experiment is an average of 108 boys EQ EQ, girls average value is 92, the average of 113 for the male students' EQ 99.55, girls, men and women have different degrees of improvement. The experimental results show that, the teaching reform in teaching, the goal setting (short-term)) to psychology, to intervene in the students of the experimental group, before and after the experiment, the data were paired samples $\mathrm{T}$ test analysis, display results: goal setting teaching before and after the experiment, students' emotional intelligence mean difference $6, \mathrm{~T}$ value 5.542 , significant at $0<0.01$. The experimental effect is obvious.

\section{Suggestions}

\section{A. Increase the EQ education for College Students}

According to the characteristics of psychological development of college students are not mature enough, the school should be targeted to set up related courses, conduct awareness of mental health knowledge lectures, setting up psychological counseling services, and through the school, the school radio station, campus network carrier, vigorously popularize mental health knowledge. Guide students to control their emotions, to enhance the social strain, learn to deal with the contradiction of reality and desire, learn self psychological adjustment, eliminate the psychological perplexity, improve the ability to withstand and deal with setbacks. Education students to correctly treat the success and failure, and able to learn from the experiences and lessons; help the students to form healthy psychology.

EQ education for college students is a systematic project, and the University as a training base, more responsibility and obligation in the students' EQ education. Colleges and universities should give full play to the role of students' education and management system, existing in the EQ education students' comprehensive operation, catch condominium together, to provide students with platform to promote emotional intelligence level.

Guide students to establish harmonious interpersonal relationships pay attention to teaching, guide students to abandon the inferiority complex, full of confidence to the life, being open to people, make their own psychological in relaxed and happy; guide to help students learn to get along with others, to cultivate the spirit of unity and cooperation.

\section{B. To create teaching situation,}

So that students in physical education to improve the EQ EQ is essentially valid personal self adjustment ability and adapt to a variety of external environment. [5] In general, psychological guidance can make clear how they should be done in some cases of college students, but to make this really into practical ability of their own, must through the practice exercise. Efforts to create the sports situational teaching, to enable students to practice, are the primary condition for the cultivation and development offer. Lu You a poem: "paper come Zhongjue shallow, no matter known to practice." Sports teaching are students' physical and mental activities, to create the scene teaching according to the actual situation of college students in college physical education, improve the quality of College Students' Eq. As in sports dance teaching in the creation of "weekend Dances" situation, improve students' confidence and courage to continue in this way, training the not afraid of difficulties, to overcome difficulties will quality, thus gradually enlarge students 'psychological space, enhance their psychological endurance, improve students interpersonal status.

\section{References}

[1] Zhang Ce, Tang Yanking, Wang Hoxie, Zhao Hinge. Review. Journal of Beijing Sport University sports dance course in Colleges and universities in China, 2009 (09)

[2] Chen Xi. Present situation and Countermeasures. Journal of Beijing Sport University of China's College Dance Sport Development in 2006 (02)

[3] Ni Xing, leaf Wei. The status of sports dance course in college physical education teaching and the role of the. Sports and science. 2006 (03)

[4] Jiang Wei, Jiao Jean. Physical education in public colleges and universities offering the physical dance course examines. Journal of Beijing Sport University. 2006 (10)

[5] Hou Ye. Affected the mental health of college students. On the two elements of the. Youth literature. 2011 (02)

[6] Zhang Yan. Group counseling on College Students' mental health training effect of. 2011 (20) men

[7] Xian Zhejiang, Tang Quipping, Chang Xian, Deng Yeanling. 457 college students psychological abuse and neglect in childhood experiences and mental health Chinese. Journal of clinical psychology. 2008 (01) 